\title{
THE PROPHYLACTIC USE OF SULFANILAMIDE IN STREPTO- COCCAL RESPIRATORY INFECTIONS, WITH ESPECIAL REFERENCE TO RHEUMATIC FEVER ${ }^{1}$
}

\author{
By ALVIN F. COBURN AND LUCILE V. MOORE \\ (From the Department of Medicine, College of Physicians and Surgeons, Columbia University, \\ and the Presbyterian Hospital, New York City)
}

(Received for publication October 11, 1938)

The close association of rheumatic fever with hemolytic streptococcal infections has led several investigators to test the applicability of sulfanilamide to the treatment of this disease. The results $(1,2)$ have indicated that the drug is of no therapeutic value in acute rheumatism. In fact, unlike those diseases which merely fail to respond to sulfanilamide therapy, rheumatic fever is definitely aggravated by the drug. This is not surprising if one considers the unusual sensitivity of paiients with active rheumatism to streptococcal products.

Our observations over the past ten years have shown that rheumatic subjects who escaped hemolytic streptococcal infections also escaped rheumatic fever. It therefore seemed possible that the development of rheumatic attacks might be avoided if streptococcal respiratory infections could be prevented. With this objective in mind, we have conducted studies in the prophylaxis of hemolytic streptococcal infections during the past two years. The data to be reported comprise experiments on guinea pigs and observations on rheumatic subjects.

\section{EXPERIMENTS ON GUINEA PIGS}

Streptococcal cervical lymphadenitis or "lumps," an epizootic disease originally described by Smith (3), was selected as a close parallel in the guinea pig to pharyngitis in the human subject. The prophylactic effect of sulfanilamide was therefore tested on both spontaneous and induced infections of this character.

\section{EXPERIMENTAL PROCEDURE}

1. Spontaneous infections were obtained in healthy guinea pigs weighing about 250 grams during the winter months by placing one infected animal in each of two groups of 15 normals. To equalize the virulence of in-

\footnotetext{
1 The work reported in this communication was carried
} out under the W. K. Kellogg Foundation Fund. fection to which the healthy pigs were exposed, the infected animals (kindly furnished by Dr. C. V. Seastone of the Rockefeller Institute, Princeton) were alternated daily between the two groups, one of which received sulfanilamide, the other not.

2. Induced infections. In order to avoid the delay involved in the spontaneous transmission of infection through a colony, a matter of many weeks, more severe infections were induced by the introduction of $0.2 \mathrm{cc}$. of an 18-hour culture of hemolytic streptococcus Group C, Seastone's strain, Number L7628, into the nares of each pig. The second and third colonies were infected in this way.

3. Sulfanilamide was administered by hypodermoclysis. In the course of 24 hours, each animal received 0.15 gram in the form of a 1 per cent solution of the drug in normal saline. Doses were administered every eight hours. This amount of medication maintained a concentration in heart's blood of 80 to 100 gamma per cc.

4. All animals were examined daily for signs of lymphadenitis.

5. Bacteriological studies were made on pigs which died and on those which were killed. The tissues cultured were lymph glands, heart's blood, liver, spleen, and lung. Cultures were made in broth and on blood agar plates, incubated under both aerobic and anaerobic conditions.

6. Histological studies were made from fixed preparations of the infected foci as well as from lymph glands, lung, liver, spleen, and kidney.

The first colony of 30 animals, exposed to infection by contact with diseased guinea pigs, was divided into two groups: (a) 15 treated with sulfanilamide and $(b) 15$ controls. The period of exposure was 7 weeks. At the end of this time all 15 of the untreated controls had developed cervical adenitis, and 13 yielded hemolytic streptococcus Group C. At the same time, none of the treated pigs had palpable cervical glands. At autopsy the cervical nodes of 6 animals were slightly larger than normal. Cultures of the entire treated group were negative for hemolytic streptococcus. Although these experiments differed considerably in detail from those of Seastone (4) our observations are in good agreement with his. 
The second colony of 24 pigs, infected by the introduction of $0.2 \mathrm{cc}$. of culture in the nares, was divided into two groups, (a) 12 treated with sulfanilamide before and after insufflation of culture, and (b) 12 untreated controls. Within three weeks all controls developed marked enlargement of the cervical glands from each of which hemolytic streptococcus Group C was cultured. The treated animals appeared to be normal. They were killed at this time and on autopsy the cervical glands were found to be slightly enlarged in all pigs. However, hemolytic streptococcus Group $\mathrm{C}$ was isolated from only 4 of the 12 pigs.

The occurrence of slight cervical enlargement and the absence of organisms on culture or smear in 8 animals suggested that organisms might be present in the glands and be controlled by the bacteriostatic action of sulfanilamide. The following experiment investigated this possibility. A third colony of 24 pigs were all treated with sulfanilamide before and after infection by the nasal route. After 14 days chemotherapy was discontinued. Half of the animals were killed (Group 1). Their cervical glands were removed under sterile precautions, ground, and injected into the abdomen of 12 normal pigs (Group 3 ). The remaining 12 pigs (Group 2) were kept without further medication.

One month later Groups 2 and 3 were sacrificed. The animals in Group 3 were all found to be normal and all cultures were sterile. Hemolytic streptococcus was recovered from 4 out of 12 pigs in Group 2.

In summary, sulfanilamide appeared to give complete protection to a colony of guinea pigs against spontaneous lymphadenitis with Group C hemolytic streptococcus. Sulfanilamide seemed to protect about two-thirds of the animals which received a large dose of the same organisms intranasally, and modified the disease in the remaining third.

\section{CLINICAL STUDIES}

\section{Study $I$}

Limited observations (5) had suggested that the incidence of septic complications following streptococcal infections might be diminished by sulfanilamide therapy during the infections. We therefore investigated the effect of sulfanilamide, administered during pharyngitis, on the incidence of rheumatic recrudescences.

The patients were selected from a group of rheumatic subjects who have been under our observation for a number of years. Each hemolytic streptococcal throat infection that was seen by us within 24 hours of the onset of symptoms was treated for 5 to 14 days with sulfanilamide. Patients who contracted similar infections but did not report their symptoms until after 24 hours were used as controls. Careful observations were made on a group of 40 children and young adults. The results are summarized in Table I.

TABLE I

The effect of sulfanilamide administered during pharyngitis on the incidence of rheumatic recrudescences in rheumatic subjects

\begin{tabular}{|c|c|c|c|}
\hline \multicolumn{2}{|c|}{ Treated with sulfanilamide } & \multicolumn{2}{|c|}{ Not treated with sulfanilamide } \\
\hline Patient & $\begin{array}{l}\text { Severity of } \\
\text { rheumatic } \\
\text { attack }\end{array}$ & Patient & $\begin{array}{l}\text { ity of } \\
\text { natic } \\
\text { ack }\end{array}$ \\
\hline 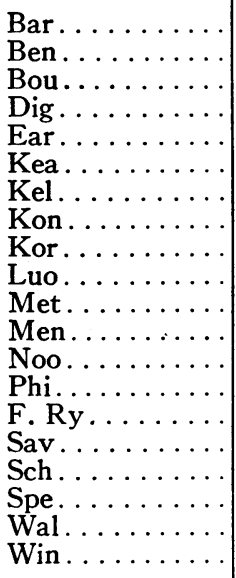 & $\begin{array}{l}++ \\
+++ \\
+ \\
0 \\
++++ \\
0 \\
+ \\
\pm \\
0 \\
+ \\
++ \\
0 \\
0 \\
+++ \\
\pm \\
\pm \\
0 \\
0 \\
+ \\
+\end{array}$ & 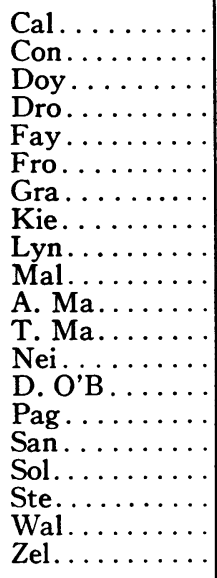 & $\begin{array}{l}0 \\
0 \\
0 \\
+++ \\
+ \\
0 \\
0 \\
+++ \\
0 \\
++++ \\
0 \\
++ \\
+++ \\
++ \\
++++ \\
+++ \\
0 \\
+ \\
+ \\
0\end{array}$ \\
\hline \multicolumn{2}{|c|}{ Total number of cases 20} & \multicolumn{2}{|c|}{ Total number of cases 20} \\
\hline \multicolumn{2}{|c|}{ 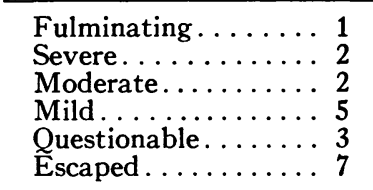 } & \multicolumn{2}{|c|}{ 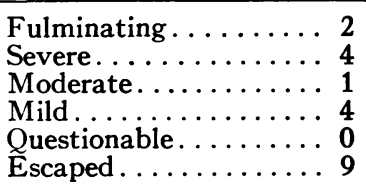 } \\
\hline
\end{tabular}

From Table $I$ it is seen that 13 treated cases ${ }^{2}$ and 11 untreated cases developed rheumatic

2 The antistreptolysin responses of these patients were similar to those which occurred in untreated rheumatic subjects who developed attacks. 
manifestations. The latter were possibly a little more severe. Sulfanilamide therapy begun after the onset of pharyngitis appeared to have no effect as a prophylactic agent in preventing rheumatic recrudescences. These findings are in accord with the observations of Massell (1).

The efficacy of sulfanilamide in preventing guinea pigs from contracting spontaneous Group $C$ infections suggested that it might also be of use in preventing the occurrence of Group A respiratory infections in human subjects. To investigate this possibility three additional clinical studies were carried out.

\section{Study 2}

Procedure. The patients were 29 rheumatic girls between the ages of 6 and 14 who were convalescing at the Pelham Home. The majority were quiescent, a few had evidences of smouldering rheumatism. Except for monthly visits from relatives, their contacts were limited to the personnel of Pelham Home. ${ }^{3}$ No new patients were admitted to the Home during the experiment, which ran from January 9 to June 17, 1937.

Each patient was given by mouth approximately 2 grams of sulfanilamide daily, divided into three doses distributed as evenly as possible throughout the 24 hours. Medication was maintained for the whole period of observation. Previous experience (5) had shown that drug symptoms occurred less frequently in children than in adults and did not develop later than two weeks from the start of therapy.

Two throat cultures were obtained from each patient once a week. In addition, cultures were taken of all patients at the onset of any respiratory infection.

Blood sedimentation rates were determined twice a month. Urinalysis and blood counts were done several times during the course of the experiment.

A careful clinical history was taken daily and a physical examination made once a week.

Results. No patients developed any drug manifestations. A few showed slight anorexia and failed to gain weight. There was no evidence of blood destruction or renal irritation.

Hemolytic streptococcus was present in the throat flora of 6 patients at the time medication was started. Two of these were carriers, and continued to harbor the organism throughout most of the period. The other 4 became negative within a month after the drug was started. Hemolytic streptococcus appeared briefly in the

8 The Pelham Home is a convalescent home caring for 30 girls with rheumatic heart disease. The personnel comprises a teacher, 3 nurses, and 3 domestics. throat flora of one other patient at about the middle of the period of observation.

The clinical results may be described as follows: (a) Four patients who already had hemolytic streptococcus in the throat flora at the start showed brief mild rheumatic recrudescences within a few days after starting sulfanilamide. (b) Six patients experienced vague symptoms. It was impossible to know whether these were related to rheumatic activity. (c) Nineteen patients were entirely symptom-free throughout the period.

The blood sedimentation rates remained nor$\mathrm{mal}$ in all but 5 individuals. Four of these rises were transient, occurring in the patients who developed rheumatic symptoms on starting the drug. The fifth occurred during a severe attack of bronchitis.

In summary, during the course of the study there were no drug symptoms, no frank streptococcal infections, and no attacks of acute rheumatism. Sulfanilamide did not prevent the occurrence of a number of "common colds," one pneumococcus ear infection, and one severe bronchitis of unknown etiology.

\section{Study 3}

The findings in Study 2 again suggested that sulfanilamide might be of prophylactic value in streptococcal respiratory infections. The third study was planned to obtain critical information on a group of rheumatic children known to be exposed to hemolytic streptococcal infection. In the foregoing study which was performed in a closed colony, there was no indication that the patients had contact with streptococcal infection other than their association with two known carriers of this organism. In the course of Study 3, 4 new patients were admitted to The Pelham Home at different times. One of these was recovering from pharyngitis, another from tonsillectomy, and the other two had acute rheumatism.

Procedure. The general procedure was the same as in Study 2, with certain exceptions, as follows:

(a) Six patients from whom sulfanilamide was withheld for various reasons served as untreated controls.

(b) The dosage level was raised gradually over the first 2 weeks to approximately 2 grams per patients per day. 
(c) The concentration of sulfanilamide in the blood was determined every two weeks. Blood samples were collected at various times after medication to include diurnal fluctuations.

Results. As in Study 2, no patient developed drug manifestations, but failure to gain weight was noted in a few instances.

The blood sulfanilamide concentration remained fairly constant after the maintenance dosage was established. The average blood concentration for all patients varied between 29 and 55 gammas per cc. with a general average of 39 gammas for the whole group. The individual data are presented in Table II.

TABLE II

The concentration of sulfanilamide expressed as gammas per cc. in the blood of rheumatic children kept on maintenance medication at The Pelham Home from November 1937 to June 1938

\begin{tabular}{|c|c|c|c|c|c|c|c|c|c|c|c|}
\hline 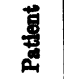 & $\frac{\text { 흉 }}{\text { है }}$ & \% & 客 & \$் & $\stackrel{\text { ต }}{\leftrightarrow}$ & 串 & 悹 & $\dot{8}$ & $\underset{\Delta}{\mathbb{d}}$ & 总 & $\begin{array}{l}8 \\
\frac{8}{8} \\
\frac{8}{4}\end{array}$ \\
\hline $\begin{array}{l}\text { Ava.. } \\
\text { Cap.. } \\
\text { Cia.. } \\
\text { Edw. } \\
\text { Fah. } \\
\text { Gor. } \\
\text { Gre.. } \\
\text { Hob. } \\
\text { Ira.. } \\
\text { Lb.. } \\
\text { Lib.. } \\
\text { Mas. } \\
\text { Mor. } \\
\text { O'Br. } \\
\text { Rio.. } \\
\text { Ros. . } \\
\text { Bal... }\end{array}$ & $\begin{array}{r}\text { Dbs. } \\
63 \\
100 \\
78 \\
78 \\
\\
46 \\
46 \\
102 \\
75 \\
108 \\
62 \\
50 \\
100 \\
67 \\
79 \\
100 \\
110\end{array}$ & $\begin{array}{c}\text { orams } \\
2 \\
2 \\
2 \\
2 \\
\\
2 \\
2 \\
2 \\
2 \\
2 \\
2 \\
2 \\
8 \\
2 \\
2 \\
2 \\
2\end{array}$ & $\begin{array}{|cc|}18 & 38 \\
0 & 18 \\
8 & \\
18 & \\
20 & 58 \\
10 & 20 \\
18 & 54 \\
10 & \\
15 & \\
10 & 34 \\
22 & 38 \\
22 & 42 \\
10 & 18 \\
24 & 22 \\
8 & \\
12 & 36 \\
14\end{array}$ & $\begin{array}{ll}30 & 32 \\
30 & 25 \\
10 & 15 \\
30 & 52 \\
50 & 56 \\
30 & 32 \\
54 & 55 \\
30 & 45 \\
36 & 52 \\
44 & 30 \\
40 & 35 \\
60 & 53 \\
26 & 18 \\
36 & 35 \\
32 & 45 \\
20 & 25 \\
28 & 45\end{array}$ & $\begin{array}{lll}55 & 40 \\
30 & 35 \\
35 & 40 \\
25 & 35 \\
30 & 35 \\
30 & 35 \\
35 & 55 \\
18 & 30 \\
25 & 40 \\
40 & 40 \\
55 & 40 \\
33 & 48 \\
30 & 55 \\
40 & 50 \\
45 & 40 \\
35 & \\
20 & \end{array}$ & $\begin{array}{ll}40 & \\
40 & \\
35 & 35 \\
40 & 38 \\
& \\
40 & 40 \\
55 & 70 \\
35 & \\
30 & 40 \\
40 & \\
40 \\
45 \\
55 \\
55 \\
35 & 40 \\
40 & 32 \\
20 & 20 \\
30 & 30\end{array}$ & \begin{tabular}{|lll}
33 & 35 \\
28 & 30 \\
35 & 40 \\
35 & 32 \\
36 & \\
36 & 48 \\
55 & 60 \\
& 28 \\
40 & 33 \\
35 & 35 \\
14 & 35 \\
40 & 50 \\
35 & 35 \\
5 & 88 \\
33 & 85 \\
28 & 82 \\
30 & 35
\end{tabular} & $\begin{array}{|ll|}60 & 35 \\
40 & 20 \\
50 & 38 \\
60 & 37 \\
40 & 35 \\
50 & 35 \\
25 & 40 \\
55 & 45 \\
20 & 40 \\
45 & 50 \\
70 & 55 \\
33 & 40 \\
50 & 40 \\
30 & 40 \\
40 & 20 \\
55 & 35\end{array} \mid$ & $\begin{array}{lll}35 & 55 \\
25 & 45 \\
40 & 35 \\
40 & 45 \\
50 & 40 \\
45 & 35 \\
40 & 35 \\
55 & \\
40 & 50 \\
45 & 70 \\
55 & 60 \\
60 & 45 \\
55 & 40 \\
40 & \\
45 \\
30 & 35\end{array}$ & $\begin{array}{l}50 \\
35 \\
45 \\
50 \\
45 \\
60 \\
35 \\
50 \\
50 \\
35 \\
50 \\
50 \\
35 \\
40\end{array}$ & $\begin{array}{l}39 \\
31 \\
34 \\
40 \\
42 \\
39 \\
51 \\
33 \\
42 \\
38 \\
43 \\
50 \\
40 \\
35 \\
37 \\
29 \\
34\end{array}$ \\
\hline $\begin{array}{l}\text { Ban.. } \\
\text { Scas.. } \\
\text { Spe... } \\
\text { 8te... } \\
\text { Tag.. } \\
\text { Vol.. } \\
\text { Wei.. }\end{array}$ & $\begin{array}{r}53 \\
88 \\
106 \\
47 \\
87 \\
98 \\
67\end{array}$ & $\begin{array}{l}\mathbf{2} \\
2 \\
2 \\
2 \\
2 \\
2 \\
2\end{array}$ & $\begin{array}{c}20 \\
628 \\
15 \\
10 \\
1432 \\
8\end{array}$ & \begin{tabular}{lll|}
36 & 55 \\
28 & 20 \\
36 & 60 \\
40 & 53 \\
& 40 \\
30 & 52
\end{tabular} & $\begin{array}{ll}40 & 35 \\
40 & \\
30 & 35 \\
50 & 35 \\
30 & \\
20 & 35 \\
30 & \end{array}$ & $\begin{array}{ll}\mathbf{5 5} & \mathbf{5 5} \\
\mathbf{2 5} & \mathbf{2 5} \\
\mathbf{3 0} & \mathbf{3 0} \\
\mathbf{5 0} & \mathbf{6 0} \\
\mathbf{3 5} & \mathbf{3 5} \\
\mathbf{3 5} & \mathbf{3 3} \\
\mathbf{3 5} & \mathbf{4 0}\end{array}$ & \begin{tabular}{|ll}
50 & 40 \\
25 & 33 \\
30 & 25 \\
55 & 55 \\
30 & 35 \\
30 & 22 \\
40 & 32
\end{tabular} \mid & \begin{tabular}{lll|}
50 & 35 \\
40 & 40 \\
40 & 30 \\
85 & 55 \\
40 & 35 \\
40 & 30 \\
40 & 35
\end{tabular} \mid & $\begin{array}{lll}\mathbf{3 5} & 50 \\
35 & \\
40 & 25 \\
65 & 55 \\
40 & 55 \\
30 & 35 \\
45 & 40\end{array}$ & $\begin{array}{l}40 \\
15 \\
30 \\
55 \\
45 \\
35 \\
15\end{array}$ & $\begin{array}{l}46 \\
29 \\
31 \\
55 \\
40 \\
32 \\
36\end{array}$ \\
\hline \multicolumn{3}{|c|}{$\begin{array}{l}\text { Patients } \\
\text { (total number) } 25\end{array}$} & & & & & & & & & 39 \\
\hline
\end{tabular}

Altogether 26 patients received sulfanilamide for considerable periods. At the start of the study, hemolytic streptococcus was present in the throat flora of 2 patients. One (Rio) was a carrier who remained positive throughout. The other (Kov) was recovering from pharyngitis and soon became negative. Of 25 other patients whose throat flora were negative at the start of the study and who received sulfanilamide, in only 2 was it possible to find a positive culture of hemolytic streptococcus at any time. In one of these the organism appeared for 48 hours in moderately large numbers, coincident with respiratory symptoms ( $\mathrm{Vol}$ ). In the other, 3 or 4 colonies were isolated from each of 3 widely spaced cultures. They were not accompanied by symptoms of any sort.

Of the 6 unmedicated patients, 4 had hemolytic streptococcus in the throat flora on one or more occasions. These data are summarized in Table III.

The clinical results showed that 25 out of the 26 medicated patients remained free of rheumatic activity. One patient developed changes which could be interpreted as active rheumatism. This girl (Vol) had a respiratory infection and cervical adenitis and maintained a high blood sedimentation rate over a period of several months in the absence of fever, tachycardia, rise in antistreptolysin titer, and rheumatic symptoms. It seems wisest to classify this case as rheumatic activity, although it was not possible to make a definite diagnosis.

The absence of rheumatic activity in patients receiving sulfanilamide is well illustrated by the sedimentation rates listed in Table IV.

In summary, these observations showed that quiescent rheumatic subjects can be maintained for many months at a high blood sulfanilamide level without demonstrable ill effects. These patients were visited by their families, were exposed to 2 patients with streptococcal infections who were introduced into The Pelham Home, and lived in close proximity with a carrier of hemolytic streptococcus and with 6 non-medicated patients who had positive cultures or rheumatic activity or both at some time during the experiment. Only one of the 26 medicated patients contracted an infection with hemolytic streptococcus in the throat flora. Twenty-five highly susceptible rheumatic children were maintained in good health throughout the winter and spring months.

\section{Study 4}

Although the patients in Study 3 were living in close contact with one another in a small institution, nevertheless their general environment with respect to nutrition, housing, and rest facilities was much better than that in which the average rheumatic child in New York City lives. 
TABLE III

The occurrence of hemolytic streptococcus in the throat flora of rheumatic children at The Pelham Home from October 1937 through June 1938

\begin{tabular}{l|l|l|l|l|l|l|l|l|l|l}
\hline \hline Patient & Oct. & Nov. & Dec. & Jan. & Feb. & Mar. & Apr. & May & June & Comments \\
\hline
\end{tabular}

RECEIVED SULPANILAMTE

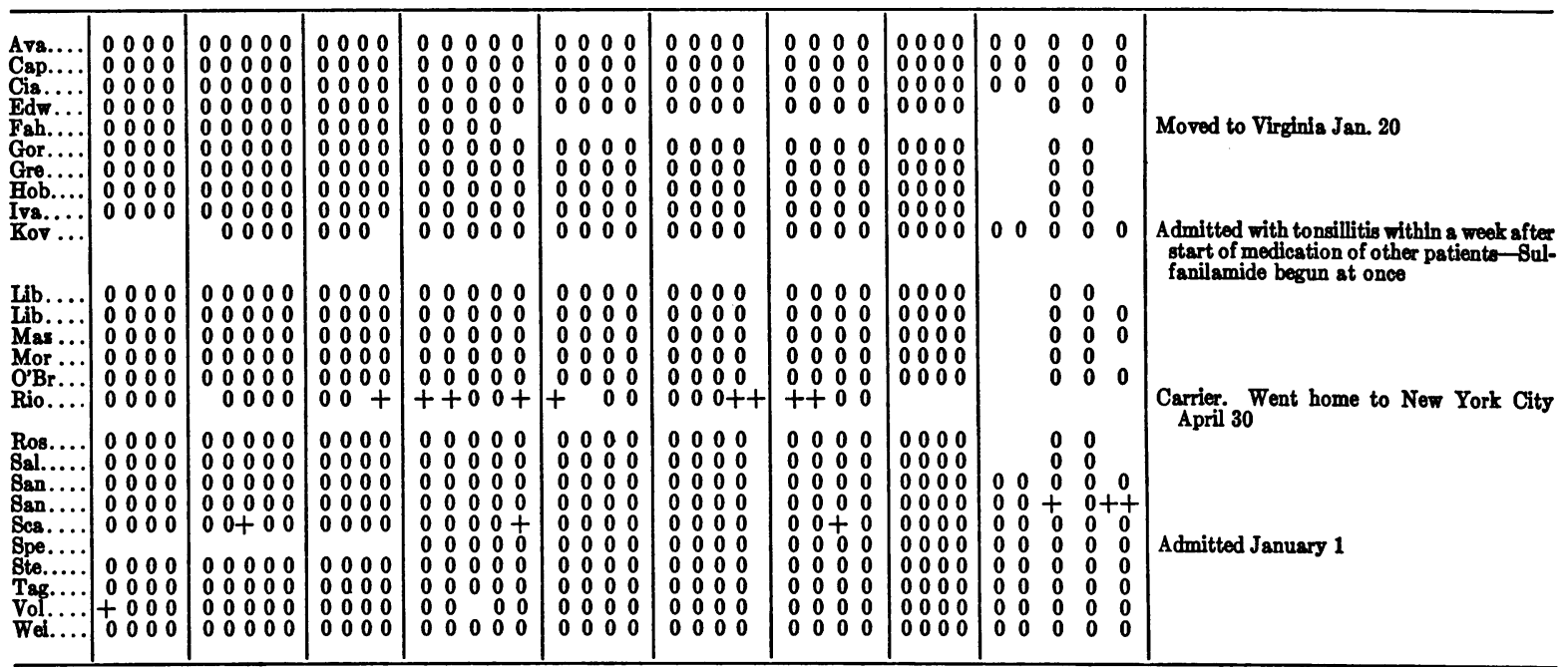

ONODICATED

\begin{tabular}{|c|c|c|c|c|c|c|c|c|c|c|c|}
\hline $\begin{array}{l}\text { Cor.... } \\
\text { Ear.... } \\
\text { MoG... } \\
\text { She.... } \\
\text { Sus.... } \\
\text { Toc.... }\end{array}$ & $\begin{array}{rlll}0 & 0 & 0 & 0 \\
0 & 0 & 0 & 0 \\
0 & 0 & 0 & 0 \\
0 & 0 & 0 & 0 \\
+ & 0 & 0 & 0\end{array}$ & $\begin{array}{lllll}0 & 0 & 0 & 0 & 0 \\
0 & 0 & 0 & 0 & 0 \\
0 & 0 & 0 & 0 & 0 \\
0 & 0 & 0 & 0 & 0 \\
0 & 0 & 0 & 0 & 0\end{array}$ & $\begin{array}{llll}0 & 0 & 0 & 0 \\
0 & 0 & 0 & 0 \\
0 & 0 & 0 & 0 \\
0 & 0 & 0 & 0\end{array}$ & 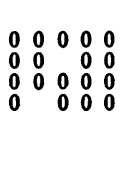 & 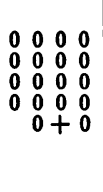 & $\begin{array}{llll}0 & 0 & 0 & 0 \\
0 & 0 & 0 & 0 \\
0 & 0 & 0 & 0 \\
0 & 0 & 0 & 0 \\
0 & 0 & 0 & 0\end{array}$ & $\begin{array}{llll}0 & 0 & 0 & 0 \\
0 & 0 & 0 & 0 \\
0 & 0 & 0 & 0 \\
0 & 0 & 0 & 0 \\
0 & 0 & 0 & 0\end{array}$ & $\begin{array}{llll}0 & 0 & 0 & 0 \\
0 & 0 & 0 & 0 \\
0 & 0 & 0 & 0 \\
0 & 0 & 0 & 0 \\
0 & 0 & 0 & 0 \\
0 & 0 & 0 & 0\end{array}$ & $\begin{array}{lll} & & + \\
0 & 0 & 0 \\
0 & 0 & 0 \\
0 & 0 & 0 \\
0 & 0 & 0 \\
0 & 0 & +\end{array}$ & $\begin{array}{ll} & + \\
0 & 0 \\
0 & 0 \\
0 & \\
0 & 0 \\
& +\end{array}$ & $\begin{array}{l}\text { Admitted May } 1 \text { with acute rheumatism } \\
\text { Left Pelham Home Nov. } 30 \text { for tonsilleo- } \\
\text { tomy. Readmitted Feb. } 1 \text { during con- } \\
\text { valescence }\end{array}$ \\
\hline
\end{tabular}

TABLE IV

The blood sedimentation rates (Westergren) of rheumatic subjects kept on maintenance medication with sulfanilamide at The Pelham Home from October 1937 through June 1938

\begin{tabular}{|c|c|c|c|c|c|c|c|c|}
\hline atient & cet. & Nov. & Dec. & Jan. & Feb. & Mar. & Apr. & May \\
\hline 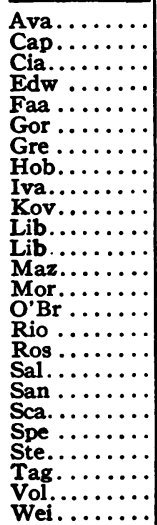 & 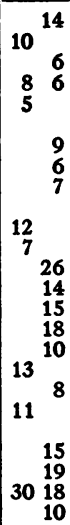 & $\begin{array}{|rr|}13 & 14 \\
7 & 8 \\
7 & 20 \\
6 & 1 \\
5 & 15 \\
20 & 10 \\
10 & 10 \\
& 4 \\
10 & 9 \\
10 & 13 \\
14 & 19 \\
7 & 4 \\
20 & 17 \\
8 & 8 \\
17 & 23 \\
12 & 15 \\
12 & 5 \\
18 & 7 \\
& 73 \\
& 13 \\
& 25 \\
22 & 26 \\
22 & 17 \\
15\end{array}$ & \begin{tabular}{|rr}
11 & 8 \\
7 & 7 \\
7 & 22 \\
5 & 5 \\
4 & 3 \\
8 & 12 \\
10 & 17 \\
4 & 7 \\
4 & 4 \\
8 & 7 \\
8 & 8 \\
5 & 3 \\
9 & 13 \\
12 & 12 \\
14 & 9 \\
10 & 13 \\
7 & 7 \\
12 & 6 \\
5 & 4 \\
13 & 10 \\
60 & 20 \\
6 & 6 \\
14 & 13 \\
7 & 12 \\
8 & 7
\end{tabular} & $\begin{array}{|rr|}7 & 7 \\
7 & 7 \\
10 & 5 \\
5 & 8 \\
3 & 20 \\
9 & 15 \\
12 & 10 \\
9 & 4 \\
8 & 4 \\
8 & 5 \\
14 & 11 \\
10 & 4 \\
13 & 13 \\
13 & 15 \\
8 & 10 \\
14 & 13 \\
16 & 13 \\
6 & 2 \\
4 & 3 \\
8 & 8 \\
6 & 12 \\
67 & 4 \\
17 & 9 \\
13 & 6 \\
15 & 2\end{array}$ & \begin{tabular}{|rr}
15 & 5 \\
4 & 5 \\
5 & 5 \\
2 & 4 \\
8 & 24 \\
4 & 6 \\
4 & 11 \\
3 & 11 \\
5 & 12 \\
8 & 7 \\
4 & 4 \\
12 & 17 \\
10 & 12 \\
7 & 8 \\
7 & 13 \\
4 & 14 \\
2 & 4 \\
2 & 4 \\
5 & 11 \\
8 & 7 \\
3 & 5 \\
15 & 12 \\
74 & 75 \\
7 &
\end{tabular} & $\begin{array}{|rr|}5 & 5 \\
4 & 4 \\
4 & 20 \\
5 & 8 \\
7 & 12 \\
8 & 5 \\
7 & 15 \\
7 & 4 \\
4 & 5 \\
10 & 6 \\
3 & 27 \\
8 & 10 \\
8 & 12 \\
8 & 6 \\
7 & 7 \\
5 & 4 \\
7 & 28 \\
5 & 5 \\
5 & 5 \\
9 & 13 \\
3 & 5 \\
13 & 10 \\
67 & 63 \\
6 & 8\end{array}$ & $\begin{array}{rr}6 & 8 \\
4 & 4 \\
4 & 9 \\
4 & 5 \\
7 & 7 \\
3 & 7 \\
3 & 3 \\
7 & 3 \\
3 & 3 \\
14 & 8 \\
3 & 10 \\
12 & 12 \\
10 & 4 \\
7 & 7 \\
8 & 13 \\
9 & 20 \\
7 & 10 \\
3 & 3 \\
7 & 10 \\
9 & 7 \\
4 & 4 \\
10 & 10 \\
44 & 46 \\
6 & 8\end{array}$ & $\begin{array}{rr}12 & 12 \\
4 & 10 \\
5 & \\
4 & 3 \\
6 & 7 \\
5 & 6 \\
7 & 3 \\
3 & 5 \\
7 & 5 \\
11 & 15 \\
12 & 11 \\
10 & 9 \\
9 & 7 \\
6 & \\
11 & 4 \\
4 & 1 \\
9 & 10 \\
5 & 3 \\
11 & 12 \\
17 & 14 \\
7 & 6\end{array}$ \\
\hline
\end{tabular}

These good conditions have not sufficed in past years to keep The Pelham Home free of streptococcal respiratory infections and rheumatic activity; however, they might have had some bearing on the results reported. A fourth study was therefore designed to test the possible protective action of sulfanilamide under conditions less favorable for the general well-being of the subjects.

This group consisted of 30 highly susceptible rheumatic subjects from 8 to 14 years of age. ${ }^{4}$ All were known to have contracted frequent streptococcal respiratory infections during previ-

4 Most of them gave a strong familial rheumatic history. All had rheumatic heart disease with at least mitral involvement. Each had had one or more frank attacks of rheumatic fever requiring hospital care. A few had had recrudescences annually during the 3 or 4 years previous to this study. 
ous years of observation. They were mostly from families with many children, living in the overcrowded rooms necessitated by their poor economic status. There was every reason to expect that many, if not all the members of the group, would contract at least one hemolytic streptococcal infection during the winter and spring months.

Procedure. Most of these children were seen about 5 times a week, and all were examined by one of us twice a month. Each child received between 2 and 3 grams of sulfanilamide daily in three doses, spaced as evenly as possible, from November 1, 1937 to July 1, 1938. Clinical examinations, throat cultures, sedimentation rates, and blood sulfanilamide determinations were made twice a month. In addition, throat cultures were obtained from parents or siblings who reported respiratory infections.

Results. Twenty of the 30 patients who started the study continued medication throughout the entire course. They will be referred to as Group A. The other ten (Group B) took the medication for only a part of the whole period, and served as controls.

In Group A none of the patients developed drug manifestations. In Group B, the appearance of drug symptoms in 3 patients made it necessary for them to discontinue sulfanilamide during the first week of the experiment.

The concentration of sulfanilamide in the blood was maintained at an average level of from 31 to 62 gammas per cc., with a general average of 41 gammas for the whole group, as shown in Table V.

Five members of Group B stopped medication during the early fall because of drug symptoms. Three of these became infected with hemolytic streptococcus during the winter.

The other five remained under medication for 4 to 7 months, during which time none showed a positive throat culture. Of 4 who remained in New York City after stopping the drug, 3 contracted hemolytic streptococcal infection within 2 months. Altogether, 6 patients in Group B became infected after stopping sulfanilamide, and 3 of these infections were followed by rheumatic recrudescences. The occurrence of hemolytic streptococcus in the throat cultures of these 30 children are presented in Table VI.

TABLE $\mathrm{V}$

The concentration of sulfanilamide expressed in gammas per cc. in the blood of rheumatic children kept on maintenance medication in New York City between November 1937 and June 1938

\begin{tabular}{|c|c|c|c|c|c|c|c|c|c|c|c|}
\hline Patient & Weight & Dose & Nov. & Dec. & Jan. & Feb. & Mar. & Apr. & May & June & Average \\
\hline 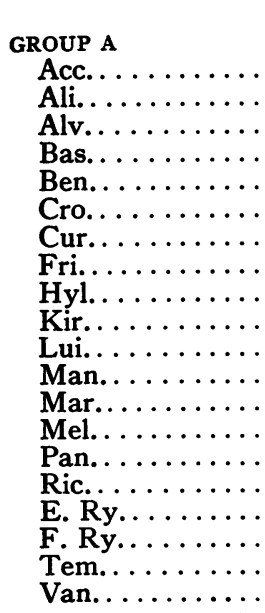 & $\begin{array}{r}\text { lbs. } \\
109 \\
88 \\
95 \\
69 \\
93 \\
85 \\
73 \\
80 \\
132 \\
101 \\
99 \\
82 \\
87 \\
98 \\
79 \\
122 \\
98 \\
90 \\
98 \\
104\end{array}$ & $\begin{array}{c}\text { grams } \\
2.3 \\
2.0 \\
2.3 \\
2.0 \\
2.3 \\
2.3 \\
2.0 \\
2.3 \\
2.3 \\
2.3 \\
2.3 \\
2.0 \\
2.3 \\
2.3 \\
2.0 \\
2.3 \\
2.0 \\
2.3 \\
2.0 \\
2.3\end{array}$ & $\begin{array}{r}12 \\
16 \\
8 \\
0 \quad 38 \\
8 \\
16 \\
10 \\
8 \\
8 \\
8 \\
6 \\
20 \\
10 \\
22 \\
6 \\
\\
8 \\
10 \\
12 \\
4\end{array}$ & \begin{tabular}{|r|r} 
& 33 \\
& 24 \\
& 15 \\
& 55 \\
& 14 \\
16 & \\
16 & \\
& 36 \\
12 & \\
20 & \\
& 22 \\
12 & \\
& 50 \\
28 & \\
& 30 \\
& \\
& \\
& 12 \\
0 & 35 \\
24 & 45 \\
35 & 30 \\
& 28
\end{tabular} & $\begin{array}{rl}57 & 60 \\
5 & 40 \\
30 & 40 \\
60 & 60 \\
40 & 60 \\
45 & 55 \\
30 & 30 \\
45 & 43 \\
30 & 30 \\
35 & 40 \\
40 & 40 \\
30 & 40 \\
35 & 40 \\
40 & 47 \\
45 & 40 \\
40 & 30 \\
10 & 33 \\
35 & 40 \\
38 & 50 \\
14 & 32\end{array}$ & $\begin{array}{ll}40 & 50 \\
55 & 37 \\
38 & 35 \\
70 & 28 \\
30 & 40 \\
40 & 45 \\
40 & 32 \\
35 & 40 \\
30 & 18 \\
33 & 30 \\
35 & 40 \\
50 & 37 \\
33 & 35 \\
40 & 50 \\
38 & 35 \\
30 & 30 \\
33 & \\
38 & 40 \\
30 & 30 \\
45 & 30\end{array}$ & $\begin{array}{rl}\mathbf{5 7} & 45 \\
32 & 35 \\
40 & 50 \\
70 & 60 \\
35 & 50 \\
57 & 60 \\
25 & 40 \\
45 & 35 \\
6 & 35 \\
30 & 45 \\
33 & 35 \\
25 & 33 \\
35 & 50 \\
50 & 40 \\
40 & 40 \\
37 & 35 \\
35 & 50 \\
55 & 55 \\
35 & 40 \\
35 & 33\end{array}$ & $\begin{array}{ll}\mathbf{5 0} & \mathbf{5 0} \\
45 & 45 \\
50 & 45 \\
80 & 55 \\
40 & 45 \\
55 & 55 \\
40 & 20 \\
60 & 50 \\
35 & 25 \\
40 & 30 \\
45 & 35 \\
40 & 35 \\
45 & 35 \\
40 & 30 \\
45 & 40 \\
35 & 25 \\
45 & 30 \\
40 & 55 \\
40 & 40 \\
35 & 30\end{array}$ & $\begin{array}{ll}60 & 90 \\
35 & 40 \\
40 & 55 \\
80 & 75 \\
& 30 \\
60 & 60 \\
45 & 20 \\
45 & 40 \\
17 & \\
50 & 50 \\
40 & 40 \\
25 & 20 \\
50 & 50 \\
50 & 50 \\
40 & 45 \\
20 & 45 \\
30 & 20 \\
55 & 55 \\
30 & 50 \\
40 & 25\end{array}$ & $\begin{array}{l}60 \\
50 \\
15 \\
60 \\
30 \\
20 \\
40 \\
30 \\
40 \\
35 \\
35 \\
45 \\
50 \\
40 \\
20 \\
55 \\
40 \\
30 \\
40\end{array}$ & 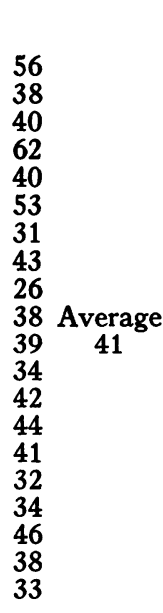 \\
\hline 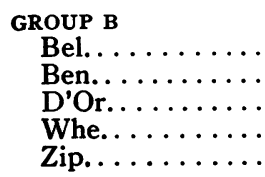 & $\begin{array}{r}48 \\
103 \\
64 \\
53 \\
107\end{array}$ & $\begin{array}{l}1.6 \\
2.3 \\
2.0 \\
2.0 \\
2.3\end{array}$ & $\begin{array}{lr}12 & 8 \\
12 \\
4\end{array}$ & $30 \begin{array}{l}33 \\
26\end{array}$ & $\begin{array}{ll}30 & 50 \\
35 & 35 \\
55 & 55 \\
& 57 \\
15 & 35\end{array}$ & $\begin{array}{ll} & 38 \\
45 & 32 \\
60 & 50 \\
& 55 \\
30 & 20\end{array}$ & $\begin{array}{ll}25 & 35 \\
30 & 35 \\
55 & 55 \\
55 & 60 \\
35 & 30\end{array}$ & $\begin{array}{lr}33 & 5 \\
30 & 35 \\
70 & 70 \\
40 & 0\end{array}$ & $\stackrel{0}{45} 45$ & 35 & $\begin{array}{lc}27 & \\
37 & \text { Average } \\
59 & 41 \\
57 & 41 \\
26 & \end{array}$ \\
\hline
\end{tabular}




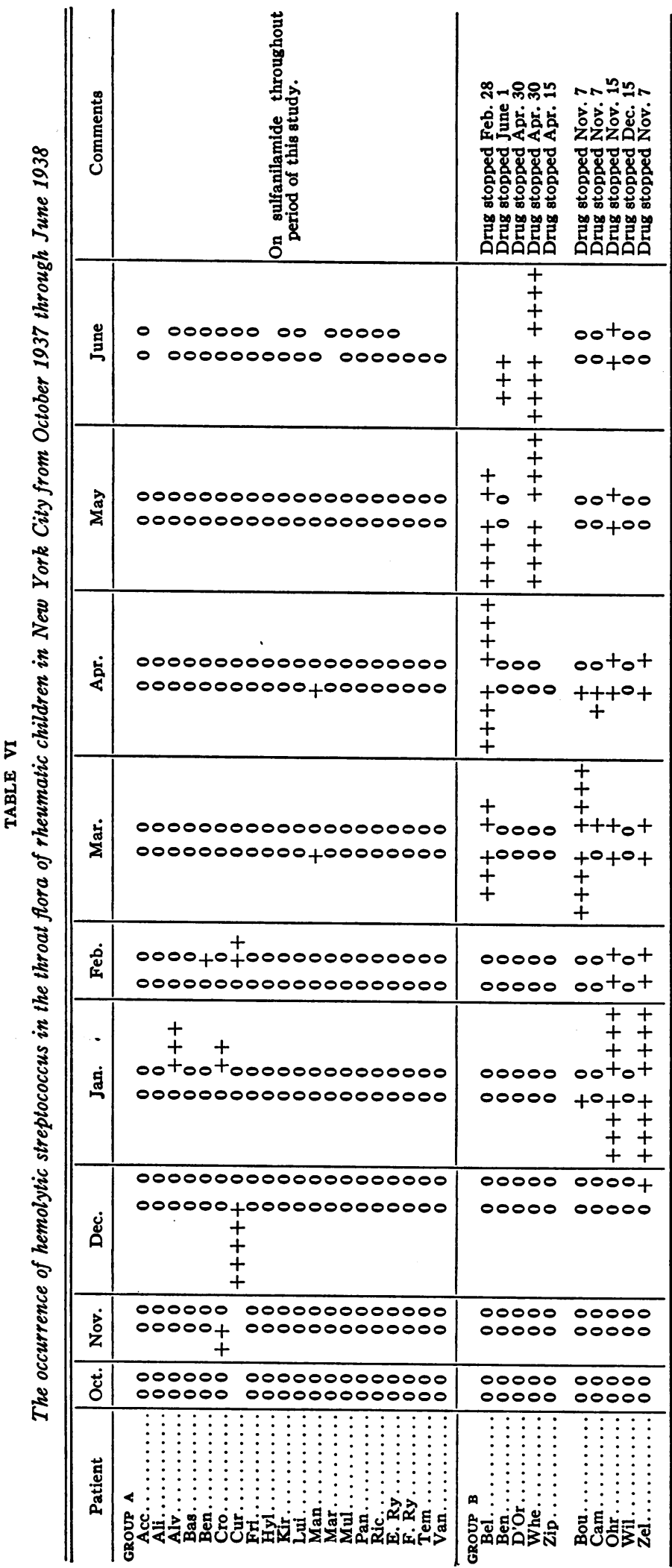


It is not possible to estimate how frequently these children were exposed to infection in their normal home and school environment. However, it was determined that epidemics of streptococcal infection occurred in the families of 3 patients in Group A and did not affect the children taking sulfanilamide.

Only one patient (Cro) had hemolytic streptococcus in the throat flora at the onset of the experiment. One patient (Cur) who was admitted to the group December 1, with cervical adenitis, and who was started on medication at once, yielded a positive culture of hemolytic streptococcus 3 days later. We could not be sure whether infection with this organism preceded or followed the administration of the drug. It was possible in 3 other patients to obtain a few colonies of hemolytic streptococcus from the throat flora on one or two occasions. None of these organisms had the mucoid or matt colony appearance of virulent strains, nor did they give rise to respiratory infections. Their cultures died in the course of 2 months' storage in blood broth before they could be classified in Lancefield's groups.

In summary, this group of 20 patients appeared to escape streptococcal respiratory infection although a number of them had "common colds" and one developed measles. They also escaped clinical evidence of rheumatic fever. Their freedom from rheumatic activity can best be visualized from the record of their sedimentation rates, given in Table VII.

\section{DISCUSSION}

The variability of hemolytic streptococcus makes it impossible to predict what the incidence of infection will be in any particular year. Past observations at The Pelham Home over a period of 10 years have shown wide annual fluctuations in the prevalence of hemolytic streptococcus. The inciderice has been as low as 25 per cent and in one epidemic year as high as 75 per cent (6). Likewise the prevalence of hemolytic streptococcal infections among our patients in New York City has varied a great deal. The average yearly incidence of infections from 1928 to 1938 was between 30 and 40 per cent. A control group of 400 non-medicated rheumatic subjects in New York City during 1938 were found to
TABLE VII

The blood sedimentation rates of rheumatic children in New York City under maintenance medication with sulfanilamide

\begin{tabular}{|c|c|c|c|c|c|c|c|c|c|}
\hline Patient & Oct. & Nov. & Dec. & Jan. & Feb. & Mar. & Apr. & May & June \\
\hline 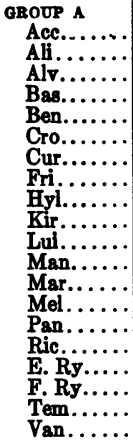 & $\begin{array}{l}30 \\
20 \\
10\end{array}$ & $\begin{array}{rr}18 & 25 \\
10 & \\
16 & 8 \\
20 & 20 \\
10 & 5 \\
10 & 15 \\
10 & \\
10 & 12 \\
3 & 10 \\
11 & 10 \\
10 & 10 \\
20 & 4 \\
10 & 6 \\
5 & 8 \\
5 & 9 \\
10 & \\
& 20 \\
10 & 15 \\
20 & \\
10 & \end{array}$ & $\begin{array}{l}30 \\
6 \\
10 \\
10 \\
7 \\
1415 \\
4 \\
12 \\
12 \\
15 \\
17 \\
25 \\
5 \\
7 \\
10 \\
5 \\
9 \\
10 \\
10 \\
8 \\
14\end{array}$ & $\begin{array}{rr}20 & 10 \\
8 & 12 \\
15 & 17 \\
25 & 20 \\
14 & 10 \\
20 & 8 \\
5 & 10 \\
5 & 15 \\
4 & 5 \\
18 & 10 \\
22 & 7 \\
10 & 3 \\
7 & 17 \\
11 & 22 \\
5 & 6 \\
14 & 10 \\
5 & 18 \\
7 & 7 \\
15 & 8 \\
5 & 20\end{array}$ & $\begin{array}{rr}15 & 10 \\
10 & 9 \\
18 & 20 \\
18 & 25 \\
8 & 12 \\
20 & 7 \\
4 & 30 \\
6 & 5 \\
10 & 4 \\
10 & 10 \\
28 & 20 \\
10 & 5 \\
12 & 6 \\
15 & 5 \\
25 & 10 \\
10 & 4 \\
7 & 8 \\
7 & 3 \\
12 & 8 \\
7 & 9\end{array}$ & $\begin{array}{rr}15 & 6 \\
8 & 4 \\
12 & 10 \\
18 & 15 \\
5 & 8 \\
15 & 6 \\
8 & 4 \\
10 & 8 \\
9 & 2 \\
15 & 9 \\
12 & 14 \\
4 & 3 \\
10 & 8 \\
6 & 9 \\
4 & 6 \\
15 & 12 \\
& \\
4 & 12 \\
10 & 17 \\
14 & 14\end{array}$ & $\begin{array}{rr}15 & 10 \\
6 & 16 \\
8 & 10 \\
32 & 15 \\
12 & 4 \\
10 & 10 \\
6 & 3 \\
6 & 5 \\
4 & 5 \\
7 & 7 \\
12 & 8 \\
4 & 4 \\
7 & 4 \\
10 & 6 \\
7 & 5 \\
10 & 8 \\
10 & 10 \\
12 & 4 \\
10 & 10 \\
10 & 8\end{array}$ & $\begin{array}{rr}18 & 5 \\
7 & 10 \\
10 & 15 \\
15 & 12 \\
4 & 7 \\
15 & 15 \\
4 & 8 \\
10 & 6 \\
7 & \\
5 & 6 \\
8 & 8 \\
10 & 4 \\
4 & 8 \\
4 & 8 \\
20 & 4 \\
5 & 6 \\
9 & 9 \\
7 & 10 \\
20 & 14 \\
12 & 8\end{array}$ & $\begin{array}{r}10 \\
6 \\
6 \\
30 \\
10 \\
14 \\
5 \\
7 \\
7 \\
5 \\
10 \\
8 \\
10 \\
10 \\
5 \\
5 \\
8\end{array}$ \\
\hline $\begin{array}{l}\text { GROUP B } \\
\text { Bel........ } \\
\text { Ben...... } \\
\text { D'Or...... } \\
\text { Whe...... } \\
\text { Zip....... } \\
\text { Bou....... } \\
\text { Cam...... } \\
\text { Ohr...... } \\
\text { Wil........ } \\
\text { Zel....... }\end{array}$ & $\begin{array}{l}8 \\
5\end{array}$ & $\begin{array}{l}915 \\
5 \\
5 \\
\\
5 \\
8 \\
512 \\
5\end{array}$ & $\begin{array}{r}25 \\
10 \\
4\end{array}$ & $\begin{array}{rr}6 & 8 \\
22 & 5 \\
12 & 10 \\
& 5 \\
5 & 22\end{array}$ & $\begin{array}{rr}12 & \\
10 & 5 \\
5 & 5 \\
7 & \\
8 & 18\end{array}$ & $\begin{array}{rr}10 & 12 \\
20 & 35 \\
10 & 10 \\
3 & 6 \\
6 & 2\end{array}$ & $\begin{array}{rr}8 & 12 \\
10 & 14 \\
5 & 7 \\
4 & 4\end{array}$ & $\begin{array}{l}20 \\
1514\end{array}$ & \\
\hline
\end{tabular}

have an incidence of 35 per cent Group A hemolytic streptococcal throat infections. The treated cases were selected because they had contracted pharyngitis frequently and experienced much rheumatic activity in the years preceding this study.

\section{SUMMARY}

Sulfanilamide administered to guinea pigs before or after the induction of streptococcal abscesses failed to sterilize the lesions.

Sulfanilamide used prophylactically prevented spontaneous infections and either prevented or modified the development of induced hemolytic streptococcal cervical adenitis in the guinea pig.

Sulfanilamide administered to rheumatic subjects after the onset of streptococcal throat infections did not prevent rheumatic recrudescences.

The possible prophylactic use of sulfanilamide was tested in 80 rheumatic children. Seventynine escaped hemolytic streptococcal infection and signs of rheumatic activity.

The authors are deeply indebted to Dr. John S. Sclater of Edinburgh and to H. E. Stokinger for their assistance in conducting these studies. 


\section{BIBLIOGRAPHY}

1. Massell, B. F., Studies on the use of prontylin in rheumatic fever. New England J. Med., 1937, 216, 487.

2. Swift, H. F., Moen, J. K., and Hirst, G. K., The action of sulfanilamide in rheumatic fever. J. A. M. A., 1938, 110, 426.

3. Smith, Theobald, Spontaneous and induced streptococcus disease in guinea-pigs: An epidemiologic study. Internat. Clin., 1931, 3, 276.

4. Seastone, C. B., The effect of sulfanilamide (paraaminobenzenesulfonamide) on Group " $C$ " hemolytic streptococcus infections. J. Immunol., 1937, 33, 403.

5. Lockwood, J. S., Coburn, A. F., and Stokinger, H. E. Studies on the mechanism of the action of sulfanilamide: The bearing of the character of the lesion on the effectiveness of the drug. J. A. M. A., 1938, 111, 2259.

6. Coburn, A. F., and Pauli, R. H., Studies on the immune response of the rheumatic subject and its relationship to activity of the rheumatic process. II. Observations on an epidemic of influenza followed by hemolytic streptococcus infections in a rheumatic colony. J. Exper. Med., 1935, 62, 137. 